\title{
Country and currency diversification of bond investments: do they really make sense for Swiss investors?
}

\author{
Nicola Carcano
}

Published online: 30 January 2007

(C) Swiss Society for Financial Market Research 2007

\begin{abstract}
The inclusion of hedged or unhedged foreign currency bonds within a strategic asset allocation is a crucial decision which should be analyzed carefully. The goal of this paper is to provide a contribution to this analysis by focusing particularly on the time horizon of the investment. Results are analyzed from the perspective of a Swiss investor. We find that over the last 21 years, investing in bonds denominated in Swiss Francs has been clearly less efficient in terms of risk-adjusted returns than investing in a hedged global bond portfolio. For short-term investors, we find robust evidence against the hypothesis of investing in unhedged foreign currency bonds. The picture changes dramatically, however, when we consider an investment horizon of 6 years and the normal case of balanced portfolios including also equities and domestic bonds. In this case, the optimal strategy for the period we analyzed would have been to hedge only the exposure to US dollar bonds.
\end{abstract}

Keywords Bonds · Currency risk - Hedging - International diversification · Optimal portfolios

JEL Classification Numbers $\quad \mathrm{F} 31 \cdot \mathrm{G} 11$

\footnotetext{
N. Carcano $(\varangle)$

Universitá della Svizzera Italiana, Lugano Via Sole 14, 6977 Ruvigliana, Switzerland

e-mail: nicola.carcano@freesurf.ch
} 


\section{Introduction}

\subsection{Goal of the paper}

Between 2002 and 2005, bonds denominated in Swiss Francs provided a monthly return in excess of the Swiss Franc risk-free rate of approximately $0.42 \%$. Compounded over 1 year, this leads to an excess return of approximately $5.15 \%$. This undoubtedly represents a good result, both in absolute terms and relative to the characteristics and history of the Swiss bond market.

As a result, it should not come as a surprise that the debate concerning the benefits of foreign currency bonds for Swiss investors has become particularly heated. Nowadays, it is common to hear from Swiss institutional investors and their consultants that unhedged foreign currency bonds should not be included in the strategic asset allocation of a diversified portfolio. In this context, the term hedging is related to the immunization of foreign currency risk against the domestic currency. Unhedged foreign currency bonds should be replaced either by hedged foreign currency bonds or by bonds denominated in Swiss Francs. Similar arguments have also been made for other bond markets, but they recently became particularly relevant for the Swiss market because of its outstanding risk-adjusted performance.

The inclusion of hedged or unhedged foreign currency bonds within a strategic asset allocation is a crucial decision, which is likely to affect the future risk-return profile of the portfolio. As such, it should be analyzed carefully. The goal of this paper is to provide a valid contribution to this analysis by focusing particularly on the time horizon of the investment.

The paper is organized in four sections. Section 1 summarizes the relevant literature as well as our theoretical and empirical framework. Section 2 presents the results of tests focusing on a time horizon of one month. Section 3 presents the results of tests focusing on time horizons of one year and longer. Section 4 summarizes our conclusions.

\subsection{Summary of the most relevant literature}

From the early days of modern finance, the issue of strategic investments in unhedged foreign currency bonds has generally been regarded as an empirical matter. From a theoretical point of view, we know that diversification is a positive feature of a strategic asset allocation, and foreign currency bonds certainly represent a source of diversification. Diversification is not, however, a goal per se: it makes sense to include an asset class in the strategic asset allocation of a portfolio if this improves the overall efficiency of the portfolio in terms of expected risk-adjusted return. The question of how much of the foreign currency risk investors should hedge is not easily answered on a theoretical basis. Black (1989) derived a universal formula for the optimal hedge ratio in an ideal world of frictionless trading and investment flows but highlighted that this hedge ratio varies between 30 and $80 \%$ depending on the value 
of parameters which in reality cannot be objectively recorded. This difficulty led scholars - like Gastineau (1995) - rather to postulate a certain hedge ratio than to determine it based on theoretical models. Still today, financial theory does not provide us with a precise and widely accepted answer to the question of the optimal hedge ratio. ${ }^{1}$

Unfortunately, also empirical studies have not converged to provide a common answer to the question of whether an investor should hedge his portfolio against foreign exchange risk, and if so, by how much. Perold and Schulman (1988) advocate a fully hedged position on the basis that foreign currency risk does not provide a commensurate return. At the other extreme, Froot (1993) argues that, according to the theory of Purchasing Power Parity, over long investment horizons, real exchange rates revert back to their means and investors should maintain an unhedged foreign currency position. Froot (1993) does, however, acknowledge that real exchange rates may deviate from their theoretical fair value over shorter horizons and currency hedging in this context is beneficial in reducing volatility. Greshin and Hadzima (1991) and Rosenberg (1991) suggest that foreign currency bonds are effective tools for diversifying the investments and making a portfolio more efficient. Systematic hedging is unlikely to be beneficial in terms of risk-adjusted returns, especially when one considers transaction costs.

More recently, Haefliger et al. (2002) analyzed five of the most important bond markets of the world - including the Swiss bond market - and concluded that a global bond portfolio is more efficient than a domestic bond portfolio if the denomination currency of a bond is systematically hedged against the reference currency of the investor. On the contrary, unhedged global bond portfolios should be avoided since they are much riskier than domestic bond portfolios and this additional risk is not sufficiently remunerated by a corresponding premium. However, this paper does not take into account the costs of hedging and the time horizon of the investment, two elements that will be central to our analysis.

Finally, Campbell et al. (2003) highlighted that foreign currencies can represent a hedging vehicle against the risk of reduced domestic real returns, as long as they tend to appreciate when real domestic interest rates fall. This Intertemporal Asset Pricing approach resembles some arguments presented 20 years earlier in an important survey paper by Adler and Dumas (1983). Campbell et al. (2003) presented empirical evidence in favor of this hypothesis and concluded that-assuming that real exchange rates are stationary and revert to their long-term mean-long-term investors of most countries should be exposed to foreign currency risk, whereas short-term investors should not. This study is limited to money market rates and does not refer to Swiss investors. However, it has the great merit of stressing the importance of mean-reverting

\footnotetext{
1 However, one point made by Black (1989) has received general acceptance on a theoretical ground. Since Jensen's Inequality leads a profit made when a currency appreciates to be always greater that the loss suffered in the depreciating currency (the so-called Siegel's Paradox), hedging the entire currency risk would not be efficient.
} 
foreign exchange rates for long-term investors. We will not analyze unhedged foreign currency bonds as a hedging vehicle against the risk of reduced domestic real returns, since it is not clear that reinvesting at a lower real money market rate represents a key risk for Swiss pension funds - as mentioned below, our representative investors - which often have their liabilities mainly expressed in nominal terms and a low level of liquidity.

\subsection{Theoretical framework}

In order to refer to concepts that are also well-known among practitioners, we will use the mean-variance portfolio analysis as the theoretical framework of this paper. One of the earliest versions of this analysis was developed by Markowitz (1952). The use of this framework is generally justified by an assumption of normality of the portfolio returns. In most cases, the assumption of normality is not violated for the portfolios and time horizons we consider in this paper. We will report on the cases for which certain evidence of non-normality emerges from the data.

Consistent with the selected framework of mean-variance portfolio analysis, the parameter we will use to rank the efficiency of the different portfolios is the Sharpe Ratio, as described by Sharpe (1970). Again, this has the advantage of being a very well-known parameter among practitioners.

\subsection{Empirical framework}

We analyzed the returns expressed in Swiss Francs provided by the world's major bond markets. The gross-of-fees returns provided by hedged foreign currency bonds were calculated by assuming a monthly hedging via forward foreign exchange contracts. The 1-month forward exchange rate was based on the spread between the 1-month interest rates for the two currencies involved. The returns reported for hedged foreign currency bonds are net of costs. The assumed level of hedging costs will be presented in the following section.

The representative investor of our study was a Swiss pension fund. Firstly, pension funds represent - with total assets in excess of CHF 450 bio. - a significant portion of the Swiss asset management market. Secondly, their asset allocation varies within official boundaries which are partially the result of legal recommendations, ${ }^{2}$ whereas this is generally not the case for private investors. These boundaries ensure a certain consistency in the asset allocation. For example, the total proportion invested in equities moves typically in a range between 15 and $35 \%$ of the total assets of the pension fund, whereas bonds denominated in Swiss Francs hardly fall below a level of $45 \%$. We will show below that the

2 Until the year 2000, Swiss pension funds were not allowed to violate a set of legal boundaries. Since then, it is possible to violate these boundaries, but the Management Board of the pension fund must be able to demonstrate the ability of the fund to sustain the risks potentially arising from these violations. 
conclusions of our study remain valid as long as the asset allocation moves within these boundaries, whereas this is not necessarily the case when the latter condition is not fulfilled.

Return figures were based on Citigroup WGBI All Maturities Total Return Indices, provided by Datastream, for government bond markets in the following locations: Switzerland, USA, UK, Euro-zone, and Japan. The period we considered ran from 31 December 1984 to 31 December 2005. For the period before 31 January 1999, we used the WGBI All Maturities Total Return Index on German Government bonds as a proxy for Euro-denominated bonds. Risk-free rates were based on the 3-month money market rates provided by Datastream. For the period before 31 January 1999, we used the rate on the German Mark as a proxy for the Euro risk-free rate.

In addition to considering regional bond markets, we also analyzed the returns offered by two global bond portfolios. The first portfolio was weighted in accordance with the JPM Global Active Index as of December 2005 (the JPM GA portfolio), whereas the second portfolio was weighted in accordance with the JPM Global Traded Index as of December 2005. These indices represent well the current geographical bond allocation of Swiss pension funds. The regional weights of these indices as of December 2005 are reported ${ }^{3}$ and have been assumed constant over our test data set. The major difference between the two indices is the proportion of bonds denominated in US dollar, which is significantly larger for the Global Traded index.

Finally, we analyzed the returns of three Balanced Portfolios including a $10 \%$ investment in Swiss equities and a $10 \%$ investment in foreign equities. Equity returns were based on the local MSCI Total Return Indices provided by Datastream. For the period before 31 January 1988, we used the MSCI Germany Index as a proxy for the MSCI EMU index. The remaining $80 \%$ of the portfolio was structured as follows:

- For the first portfolio, $80 \%$ was invested in bonds denominated in Swiss Francs.

- For the second portfolio, 50\% was invested in bonds denominated in Swiss Francs and $30 \%$ in the unhedged JPM GA portfolio.

- For the third portfolio, 50\% was invested in bonds denominated in Swiss Francs and $30 \%$ in the hedged JPM GA portfolio.

The actual strategic asset allocation of a Swiss pension fund is generally optimized in the context of an Asset and Liability Management (ALM) study. Therefore, these allocations vary from one pension fund to the other. The weights reported above for the second portfolio represent an average of the

\footnotetext{
3 The weights used for the JPM Global Active Index were $56 \%$ for bonds denominated in EURO, $30 \%$ for bonds denominated in Japanese Yen, $7 \%$ for bonds denominated in US dollars, and 7\% for bonds denominated in British Pounds. The weights used for the JPM Global Traded Index were $40 \%$ for bonds denominated in EURO, 29\% for bonds denominated in Japanese Yen, 26\% for bonds denominated in US dollars, and 5\% for bonds denominated in British Pounds. These weights were based on a simplification: bonds denominated in Canadian and Australian dollars were grouped together with bonds denominated in US dollars.
} 
Table 1 Interbank bid-ask spreads on exchange rates against the Swiss Franc (basis scenario)

\begin{tabular}{lllll}
\hline BID/ASK SPREADS & USD $(\%)$ & EUR(\%) & YEN(\%) & GBP(\%) \\
\hline Spot & 0.041 & 0.032 & 0.074 & 0.045 \\
1-Month forward & 0.045 & 0.046 & 0.091 & 0.077 \\
3-Month forward & 0.053 & 0.052 & 0.099 & 0.112 \\
\hline
\end{tabular}

The reported spreads are the lowest estimates of the average historical percentage spread for the corresponding currency among Reuters, UBS, and CS

weights we observe for rather conservative Swiss pension funds. ${ }^{4}$ The first and third portfolio are the alternatives we intend to test against the second portfolio.

\subsection{The costs of hedging}

Hedging is not a free service. There are at least two significant cost sources. The first one is represented by the bid-ask spread the hedger has to pay on the spot and forward foreign exchange markets. The second one is represented by the additional management and settlement fees that banks generally charge in order to execute a systematic hedging service. We based our analysis on two scenarios for these costs. The basis scenario represents the average level of these costs for large Swiss institutional investors. The higher-cost scenario represents the average level of these costs for smaller investors.

The sources we used in order to estimate the interbank percentage bidask spreads for the basis scenario were Reuters and the two primary market makers for the Swiss Franc foreign exchange rate: UBS and CS. Since this is supposed to represent a low-cost scenario, we selected the lowest estimate of the average historical spread among the three available sources. ${ }^{5}$ The spreads we obtained for spot and forward exchange rates are reported in Table 1.

As usual, the length of the maturity period, the volatility of the exchange rate and their lack of liquidity are factors that tend to increase the level of bid-ask spreads. We used the above-reported spreads in the following way: We

4 Consistently, we assumed a balanced geographical allocation of the regional equity markets. In fact, the foreign equity portfolio was composed as follows: $30 \%$ of US equities, $30 \%$ of Euro-zone equities, $15 \%$ of UK equities, $15 \%$ of Japanese equities, and $10 \%$ of other equities (represented by the MSCI Asia Ex-Japan Index).

5 UBS and CS bid/ask quotes were available starting from January 2000. Reuters provides longer time series of bid/ask interbank spot exchange rates against the CHF. For the EURO and the GBP, regime shifts were visible within Reuters time series on, respectively, 31.05.2001 and 31.12.1993. We believe that these shifts are due to an improvement in the quality of the data, mainly because of wider use of electronic trading platforms. On this basis, we decided not to use the data before the regime shifts. For the USD and the YEN, Reuters data were available starting from, respectively, 31.12.1993 and 30.06.1995. When we selected UBS or CS spreads, we assumed that the average reduction in the spread compared with Reuters also applied before the year 2000. 
Table 2 Assumed yearly costs of hedging (basis scenario)

\begin{tabular}{lllll}
\hline & USD $(\%)$ & EUR $(\%)$ & YEN $(\%)$ & GBP(\%) \\
\hline Spread costs 1-month hedging & 0.64 & 0.59 & 1.11 & 0.85 \\
Administration costs 1-month hedging & 0.05 & 0.05 & 0.05 & 0.05 \\
Total costs 1-month hedging & 0.69 & 0.64 & 1.16 & 0.90 \\
Spread costs 3-month hedging & 0.23 & 0.21 & 0.39 & 0.35 \\
Administration costs 3-month hedging & 0.03 & 0.03 & 0.03 & 0.03 \\
Total costs 3-month hedging & $\mathbf{0 . 2 6}$ & $\mathbf{0 . 2 4}$ & $\mathbf{0 . 4 2}$ & $\mathbf{0 . 3 8}$ \\
\hline
\end{tabular}

The spread costs of a single hedging period equal half of the spread on forward rates plus half of the spread on spot rates plus an additional charge to non-banking clients of $0.01 \%$. For monthly hedging, we multiplied this value by 12 in order to obtain the yearly cost, and for quarterly hedging, we multiplied this value by 4 . Administration costs reflect average management and settlement fees actually charged to large Swiss institutional clients by custodian banks for executing a systematic hedging service

assumed that half of the spread on forward rates was paid when the forward foreign exchange contract was opened, and we assumed that half of the spread on spot rates was paid when the forward foreign exchange contract was closed. In fact, rolling over a forward contract implies closing the old contract in the spot market and opening a new forward contract. The cost was represented by half of the spread because we assumed that the fair value of the exchange rate was the average between the bid and the ask prices. On this basis, we obtained the total interbank spread that would be paid for a single hedging period.

In the basis scenario, we assumed that the custodian bank would charge institutional clients - on top of the interbank spread - with an additional $0.005 \%$ on each of the two transactions necessary to open and close a forward foreign exchange contract. This led us to obtain the overall trading costs of a single hedging period. In order to obtain the yearly costs, we multiplied the trading costs of a hedging period by 12 for monthly hedging and by 4 for quarterly hedging.

Additional yearly management and settlement fees charged for executing a systematic hedging service have been assumed to amount to $0.03 \%$ for quarterly hedging and $0.05 \%$ for monthly hedging. These costs reflect average fees actually charged to large Swiss institutional clients.

The overall yearly costs of hedging calculated as described above are reported in Table 2. Since most institutions actually hedge on a quarterly basis (a decision supported by our cost analysis), we decided to perform our study on this basis. Except where otherwise stated, all figures for hedged bond positions will be meant to be net of the hedging costs specified in the last row of Table 2. These costs represent more than $13 \%$ of the average return provided by a global bond portfolio in excess of the risk-free rate and are likely to significantly influence our results.

For the higher-cost scenario, we assumed that hedging costs are increased by $0.125 \%$ p.a. for all currencies. Considering actual market conditions, we believe hedging costs of conscious institutions should not significantly exceed this level. 
Both scenarios of yearly hedging costs are consistent with the $0.3-0.6 \%$ range indicated by Rosenberg (1991) for global bond portfolios.

\section{Analysis for a time horizon of one month}

\subsection{Methodology}

This part of our analysis focuses on a time horizon of one month. As such, it is suitable for those investors who consider the risk-return profile of their portfolio over 1-month periods to be significantly more important than the same profile over longer time horizons.

We define the monthly compounded return over 1 -month periods for portfolio $A$ as:

$$
R_{t, A}^{(1)} \equiv \frac{P_{t, A}}{P_{t-1, A}}-1
$$

In order to calculate the Sharpe Ratio-denoted by SR - we estimate the sample mean and sample standard deviation of the excess return over the risk-free rate. These estimations were based, respectively, on the following equations:

$$
\begin{aligned}
\hat{\mu}_{R, A}^{(1)} & =\frac{1}{T} \sum_{t=1}^{T}\left(R_{t, A}^{(1)}-R_{t, f}^{(1)}\right) \\
\hat{\sigma}_{R, A}^{(1)} & =\sqrt{\frac{1}{T} \sum_{t=1}^{T}\left(R_{t, A}^{(1)}-R_{t, f}^{(1)}-\hat{\mu}_{R, A}^{(1)}\right)^{2}}
\end{aligned}
$$

In (2) and (3), $R_{t, f}$ indicates the monthly compounded risk-free rate at time $t-1$ and $T$ indicates the total number of observations contained in our data set. The superscript ${ }^{\wedge}$ indicates sample values.

On this basis, the Sharpe Ratio can be estimated as:

$$
S \hat{R}_{R, A}^{(1)}=\frac{\hat{\mu}_{R, A}^{(1)}}{\hat{\sigma}_{R, A}^{(1)}}
$$

If portfolio A contains more indices, its monthly compounded return over 1-month periods is calculated in accordance with the following equation:

$$
R_{t, A}^{(1)} \equiv \sum_{i=1}^{N} w_{i, A} R_{t, i}^{(1)}
$$


In (5), $R_{t, i}$ indicates the monthly compounded return provided by index $i$ and $w_{i, A}$ indicates the percentage weight that portfolio $A$ invests in index $i$. These weights are assumed to be constant. $N$ indicates the total number of indices in which portfolio $A$ invests.

\subsection{Results}

Our results report begins with regional bond markets. These results are summarized in Table 3. In addition to the full sample results, we also report results for the two 10-year sub-samples. The two sub-samples represent simply one-half of the full sample and no economic factor influenced their definition.

The first remarkable result reported in Table 3 is the large difference between the average excess return provided by bonds denominated in Swiss Francs in the two sub-samples (a monthly loss of $0.08 \%$ against a monthly gain of $0.31 \%$ ). This reflects a well-known phenomenon: bonds markets are subject to a dramatic long-term cyclicality. Very good phases follow very bad phases and vice versa. It is outside the scope of this paper to provide a rigorous explanation for this phenomenon. However, we know that fundamental factors like the rate of growth of the economy, the rate of inflation and its volatility, and the level of public debt heavily influence the bonds markets. And these fundamental factors tend to follow quite long and persistent cycles.

We should also emphasize that over the last 20 years, bonds denominated in Swiss Francs clearly underperformed unhedged bonds denominated in Euro, Yen, US dollars, and Pounds in terms of absolute returns. Even during the outstanding second sub-sample, only bonds denominated in Yen performed worse than bonds denominated in Swiss Francs. Furthermore, this observation is consistent with economic intuition. Switzerland is a country with a relatively low-growth economy, low inflation, a stable currency, and solid public finances. Thus, the Swiss bond market should be expected to return less than most other bond markets. The fact that the Swiss Franc has appreciated against some currencies has been largely balanced out by the interest rate spreads, as suggested by the principle of Uncovered Interest Rate Parity. This principle states that forward rates, which are based on interest rate spreads, are unbiased predictors of future spot rates.

When we consider risk-adjusted returns, we obtain a different picture. Over the whole period considered, no unhedged bonds denominated in foreign currencies scored better than bonds denominated in Swiss Francs. However, most hedged foreign currency bonds did, even if we still have not analyzed if the observed differences in terms of Sharpe ratios are statistically significant. The last observation is reinforced when we consider the results for portfolios comprising more currencies, as shown in Table 4. For each portfolio, we performed tests of the null hypothesis that the Sharpe Ratios of the tested portfolio and of the corresponding hedged portfolio are equal. The alternative hypothesis was that the Sharpe Ratio of the hedged portfolio is higher. 


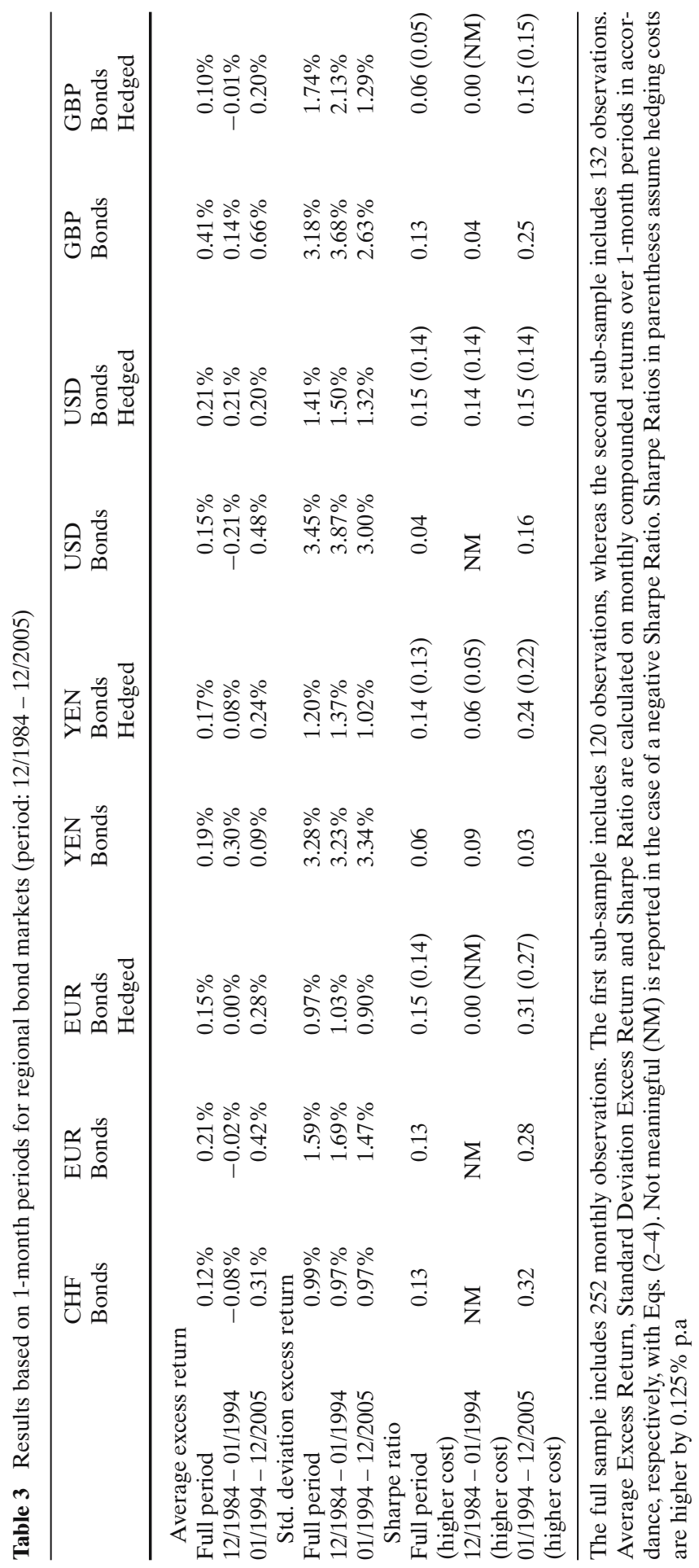


These hypothesis tests have been based on the GMM variance estimates suggested by Lo (2002) for non-IID returns. ${ }^{6}$ Their $P$-values are reported in Table 4.

The comparison between the average excess return obtained by hedged and unhedged indices shows that the principle of Uncovered Interest Rate Parity has largely held for the JPM Global Traded (i.e., the difference between the average excess return of the hedged and unhedged investment is roughly equal to the hedging costs), whereas the unhedged JPM Global Active has performed even better than expected against the Swiss Franc. Nevertheless, unhedged foreign currency bonds appear to be the least efficient investment in terms of risk-adjusted return.

On the contrary, hedged foreign currency bonds have been the most efficient investment for Swiss investors in terms of Sharpe Ratio. Their superiority with respect to the portfolio investing only in domestic bonds is more evident than in Table 3. This is consistent with intuition, since portfolios including foreign bonds denominated in multiple currencies display a higher level of diversification. This advantage becomes evident only if we hedge the foreign currency risk, because of the high short-term volatility of foreign exchange markets.

The ranking implied by these results does not change when we consider the balanced portfolios. Mainly because of the very high correlation between the two portfolios, the difference between the Sharpe Ratios of the balanced portfolio investing only in domestic bonds and of the hedged balanced portfolio is statistically significant at a $5 \%$ level.

6 Our tests of the significance of the difference between two Sharpe Ratios were based on the following $z$-scores:

$$
z_{A, B}=\frac{S \hat{R}_{A}-S \hat{R}_{B}}{\sqrt{\operatorname{var}\left[S \hat{R}_{A}-S \hat{R}_{B}\right]}}
$$

In order to estimate the denominator of this expression, we extended the approach of Lo (2002) to the covariance between the estimators of the two Sharpe Ratios for the case of non-IID returns:

$$
\begin{aligned}
C O V_{G M M}\left[S R_{A}, S R_{B}\right] & =\frac{\partial S R_{A}}{\partial \boldsymbol{\theta}_{A}} \boldsymbol{\Sigma} \frac{\partial S R_{B}}{\partial \boldsymbol{\theta}_{B}^{\prime}}, \text { which we estimate as follows: } \\
\hat{\boldsymbol{\Sigma}} & =\hat{\boldsymbol{\Omega}}_{0}^{A, B}+\sum_{j=1}^{m}\left(1-\frac{j}{m+1}\right)\left(\hat{\boldsymbol{\Omega}}_{j}^{A / B}+\hat{\boldsymbol{\Omega}}_{j}^{\prime B / A}\right) \\
\hat{\boldsymbol{\Omega}}_{0}^{u, v} & \equiv \frac{1}{T} \sum_{t=1}^{T} \varphi\left(R_{t, u}^{(1)}, \hat{\boldsymbol{\theta}}_{u}\right) \varphi\left(R_{t, v}^{(1)}, \hat{\boldsymbol{\theta}}_{v}\right)^{\prime} \\
\hat{\boldsymbol{\Omega}}_{j}^{u / v} & \equiv \frac{1}{T} \sum_{t=j+1}^{T} \varphi\left(R_{t, u}^{(1)}, \hat{\boldsymbol{\theta}}_{u}\right) \varphi\left(R_{t-j, v}^{(1)}, \hat{\boldsymbol{\theta}}_{v}\right)^{\prime}
\end{aligned}
$$

We remind that Lo (2002) identifies with $\theta$ the vector of the parameters embedded in the estimate of the Sharpe Ratio and with $\varphi\left(R_{t, u}, \boldsymbol{\theta}\right)$ the vector of the deviations from the central moments observed at time $t$. The truncation lag $m$ has been set equal to 36 months. 
Table 4 Results based on 1-month periods for global bond and balanced portfolios (period: $12 / 1984-12 / 2005)$

\begin{tabular}{|c|c|c|c|c|c|c|c|}
\hline & $\begin{array}{l}\text { JPM } \\
\text { GA }\end{array}$ & $\begin{array}{l}\text { JPM } \\
\text { GA } \\
\text { Hedged }\end{array}$ & $\begin{array}{l}\text { JPM } \\
\text { GT }\end{array}$ & $\begin{array}{l}\text { JPM } \\
\text { GT } \\
\text { Hedged }\end{array}$ & $\begin{array}{l}\text { Balanced } \\
\text { Portfolio }\end{array}$ & $\begin{array}{l}\text { Balanced } \\
\text { Portfolio } \\
\text { Hedged }\end{array}$ & $\begin{array}{l}\text { Balanced } \\
\text { Portfolio } \\
\text { with Swiss } \\
\text { Bonds only }\end{array}$ \\
\hline \multicolumn{8}{|c|}{ Average Excess Return } \\
\hline Full period & $0.21 \%$ & $0.15 \%$ & $0.20 \%$ & $0.16 \%$ & $0.27 \%$ & $0.25 \%$ & $0.24 \%$ \\
\hline $12 / 1984-01 / 1994$ & $0.08 \%$ & $0.04 \%$ & $0.03 \%$ & $0.08 \%$ & $0.10 \%$ & $0.09 \%$ & $0.05 \%$ \\
\hline $01 / 1994-12 / 2005$ & $0.34 \%$ & $0.25 \%$ & $0.35 \%$ & $0.24 \%$ & $0.42 \%$ & $0.40 \%$ & $0.42 \%$ \\
\hline \multicolumn{8}{|c|}{ Std. Deviation Excess Return } \\
\hline Full period & $1.77 \%$ & $0.91 \%$ & $1.99 \%$ & $0.94 \%$ & $1.49 \%$ & $1.23 \%$ & $1.30 \%$ \\
\hline $12 / 1984-01 / 1994$ & $1.94 \%$ & $1.03 \%$ & $2.16 \%$ & $1.04 \%$ & $1.65 \%$ & $1.39 \%$ & $1.44 \%$ \\
\hline $\begin{array}{c}01 / 1994-12 / 2005 \\
\text { Sharpe Ratio }\end{array}$ & $1.61 \%$ & $0.77 \%$ & $1.82 \%$ & $0.83 \%$ & $1.31 \%$ & $1.05 \%$ & $1.13 \%$ \\
\hline $\begin{array}{l}\text { Full period } \\
\text { (higher cost) }\end{array}$ & 0.12 & $0.17(0.16)$ & 0.10 & $0.18(0.16)$ & 0.18 & $0.20(0.20)$ & 0.19 \\
\hline$P$-value vs. hedged & $24 \%$ & & $15 \%$ & & $15 \%$ & & $4 \%$ \\
\hline $\begin{array}{l}\text { 12/1984 - 01/1994 } \\
\text { (higher cost) }\end{array}$ & 0.04 & $0.04(0.03)$ & 0.02 & $0.08(0.07)$ & 0.06 & $0.06(0.06)$ & 0.04 \\
\hline $\begin{array}{l}01 / 1994-12 / 2005 \\
\text { (higher cost) }\end{array}$ & 0.21 & $0.33(0.32)$ & 0.19 & $0.29(0.28)$ & 0.32 & $0.38(0.38)$ & 0.37 \\
\hline
\end{tabular}

Sample sizes are identical to those reported for Table 3. Average Excess Return, Standard Deviation Excess Return and Sharpe Ratio are calculated on monthly compounded returns over 1-month periods in accordance with Eqs. (2-4) respectively. JPM GA and JPM GT indicate, respectively, global bond portfolios based on the regional weights of the JPM Global Active and the JPM Global Traded indices as of December 2005. All balanced portfolios include 10\% investment in Swiss equities and $10 \%$ investment in foreign equities. The remaining $80 \%$ is invested, respectively, in bonds denominated in Swiss Francs (50\%) and in the unhedged JPM GA portfolio (30\%) (Balanced Portfolio), in bonds denominated in Swiss Francs (50\%) and in the hedged JPM GA portfolio (30\%) (Balanced Portfolio Hedged), or only in bonds denominated in Swiss Francs. Sharpe Ratios in parentheses assume hedging costs are higher by $0.125 \%$ p.a. The reported $P$-values refer to tests of the null hypothesis that the Sharpe Ratios of the tested portfolio and of the corresponding hedged portfolio are equal against the alternative hypothesis that the Sharpe Ratio of the hedged portfolio is higher

When we consider the third and the fourth moment of the distribution of returns (not reported for the sake of brevity), strong evidence of both negative skewness and leptokurtosis appears for the balanced portfolio investing in the hedged JPM Global Active index and for the one investing only in domestic

\section{Footnote 6 continued}

When $B=A$, our estimate of the covariance reduces to the estimate of the variance suggested by Lo (2002):

$$
\begin{aligned}
C O V_{G M M}\left[S R_{A}, S R_{A}\right] & \equiv V_{G M M}\left[S R_{A}\right] \\
& =\frac{\partial S R_{A}}{\partial \boldsymbol{\theta}_{A}} \boldsymbol{\Sigma} \frac{\partial S R_{A}}{\partial \boldsymbol{\theta}_{A}^{\prime}}, \text { where } \\
\hat{\boldsymbol{\Sigma}} & =\hat{\boldsymbol{\Omega}}_{0}^{A}+\sum_{j=1}^{m}\left(1-\frac{j}{m+1}\right)\left(\hat{\boldsymbol{\Omega}}_{j}^{A}+\hat{\boldsymbol{\Omega}}_{j}{ }_{j}^{A}\right) \\
\hat{\boldsymbol{\Omega}}_{j}^{A} & \equiv \frac{1}{T} \sum_{t=j+1}^{T} \varphi\left(R_{t, A}^{(1)}, \hat{\boldsymbol{\theta}}_{A}\right) \varphi\left(R_{t-j, A}^{(1)}, \hat{\boldsymbol{\theta}}_{A}\right)^{\prime} .
\end{aligned}
$$


bonds. The corresponding $t$ statistics all display absolute values larger than 2.05. On the contrary, no evidence of non-normality can be identified for the balanced portfolio investing in the unhedged JPM Global Active index. In particular, a very significant difference emerges between the positive skewness displayed by the unhedged JPM Global Active index and the negative skewness displayed by the hedged JPM Global Active index.

Summarizing, Swiss investors with a short time horizon and no strong aversion to negative skewness and leptokurtosis should have invested in hedged foreign currency bonds over the last 20 years. As indicated by our sensitivity analysis (not reported for the sake of brevity), this conclusion remains true even if the cost of hedging becomes as high as $0.7 \%$ per annum. Only investors with a very strong aversion to negative skewness and/or leptokurtosis could have preferred investments in unhedged foreign currency bonds over the last 20 years. For both types of investors, the exclusion of foreign currency bonds does not appear as an efficient decision.

\section{Analysis for time horizons of 1-year and longer}

\subsection{Methodology}

We now turn our attention to investors with a longer time horizon. If we indicate by $k$ the number of months defining the time horizon of the investor, we can set

$$
\begin{aligned}
\left(1+R_{t, A}^{(k)}\right)^{k} & \equiv \frac{P_{t, A}}{P_{t-k, A}} \\
R_{t, A}^{(k)} & =\sqrt[k]{\frac{P_{t, A}}{P_{t-k, A}}}-1
\end{aligned}
$$

Expression (7) defines the monthly compounded average monthly return calculated for portfolio $A$ on a time horizon of $k$ months ending at month $t$.

By definition, an investor focusing on a time horizon of $k$ months is not concerned about the actual monthly returns, but rather about the total return he/she will obtain over the next $k$ months. As a result, the analysis of the efficiency of a certain asset allocation can be performed on the average return defined in (7). If we select an asset allocation that leads to the highest Sharpe Ratio for the average return defined in (7), it is intuitive that we have also selected the asset allocation with the highest Sharpe Ratio for the total return defined in (6).

The total return over $k$ months can be written as the multiplication of the single monthly returns:

$$
\left(1+R_{t, A}^{(k)}\right)^{k}=\frac{P_{t, A}}{P_{t-1, A}} \frac{P_{t-1, A}}{P_{t-2, A}} \frac{P_{t-2, A}}{P_{t-3, A}} \frac{P_{t-3, A}}{P_{t-4, A}} \frac{P_{t-4, A}}{P_{t-5, A}} \cdots \frac{P_{t-k+1, A}}{P_{t-k, A}}
$$

where, for portfolios containing more indices, we calculate monthly returns in accordance with (5). From this point of view, the average monthly return can 
be defined as the geometric average of monthly returns. It is well known that it is quite difficult to calculate the statistical properties of geometric averages. For this reason, we follow the approach recommended by, among others, Campbell et al. (1997), and we base our analysis on continuously compounded monthly rates of return defined as

$$
e^{r_{t, A}} \equiv \frac{P_{t, A}}{P_{t-1, A}}
$$

We show in the Appendix how we start from the last definition and derive the following estimation of the Sharpe Ratio for the average return defined in (7):

$$
\begin{aligned}
S \hat{R}_{r, A}^{(k)} & \approx \frac{\hat{\mu}_{r, A}}{\hat{\sigma}_{r, A}^{(k)}} \quad \text { with } \\
\hat{\mu}_{r, A}^{(k)} & \equiv \hat{\mu}_{r, A}=\frac{1}{T} \sum_{t=1}^{T}\left(r_{t, A}-r_{t, f}\right) \\
\hat{\sigma}_{r, A}^{(k)} & \equiv \sqrt{\frac{1}{k}\left[\hat{\gamma}_{0, A}+2 \frac{k-1}{k} \hat{\gamma}_{1, A}+2 \frac{k-2}{k} \hat{\gamma}_{2, A}+\cdots+2 \frac{1}{k} \hat{\gamma}_{k-1, A}\right]} \\
\hat{\gamma}_{j, A} & =\frac{1}{T-j} \sum_{t=1+j}^{T}\left(r_{t, A}-r_{t, f}-\hat{\mu}_{r, A}\right)\left(r_{t-j, A}-r_{t-j, f}-\hat{\mu}_{r, A}\right)
\end{aligned}
$$

The previous equations emphasize that in addition to the sample variance (represented by the term $\gamma_{0}$ ), we also consider the auto-covariance in the estimation of the variance of the average excess return. The total effect of the auto-covariance is represented in (12) by the sum of all terms, excluding $\gamma_{0}$. We will show below that this consideration has a dramatic impact on our conclusions.

\subsection{The volatility of long-term average returns}

The change of our focus from short-term volatility to volatility of long-term average returns is so important that we should immediately analyze its implications. This implies assessing the total effect of the auto-covariance terms in (12) for the different portfolios we are considering. We report in Fig. 1, the structure of the auto-covariance of the excess returns for the unhedged JPM Global Active index and for bonds denominated in Swiss Francs.

Two crucial observations should be made in relation to Fig. 1. Firstly, the auto-covariance of an order shorter than one year [i.e., the value of Eq. (13) for $j<12$ ] is almost consistently positive for bonds denominated in Swiss Francs and, in total, larger than for the unhedged JPM Global Active index. This 


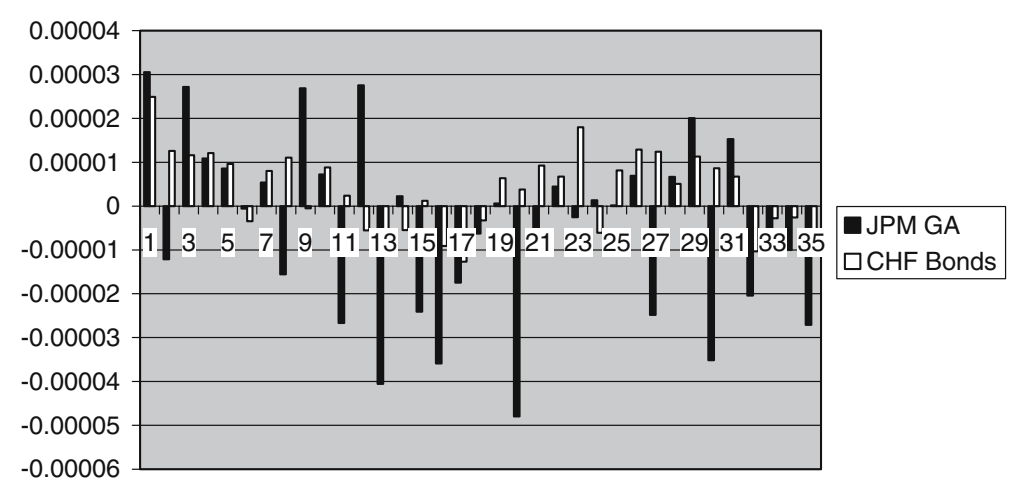

Fig. 1 Auto-covariance structure of excess returns (period: 12/1984-12/2005). Sample sizes are identical to those reported for Table 3. JPM GA indicates a global bond portfolio based on the regional weights of the JPM Global Active index as of December 2005. The numbers on the $y$-axis indicate the size of the auto-covariance of the continuously compounded excess returns as defined in (13), the numbers on the $\mathrm{x}$-axis correspond to parameter $j$ of Eq. (13)

confirms the observation already reported in Sect. 2.2: bond markets are subject to a long-term cyclicality: very good phases follow very bad phases and vice versa. ${ }^{7}$ The reason why this phenomenon is less evident for the unhedged JPM Global Active index is its diversification across different bond markets and currencies. In particular, foreign exchange markets are usually considered the most efficient of all financial markets; their returns exhibit almost no low-order auto-correlation at all.

Secondly, the auto-covariance of an order longer than one year [i.e., the value of Eq. (13) for $j>12$ ] is largely negative for the unhedged JPM Global Active index, whereas this is not the case for bonds denominated in Swiss Francs. Again, this is mainly the effect of the foreign currency exchanges, which display certain evidence of mean-reversion in the medium- and long-term. This meanreversion is consistent with the principle of the Purchasing Power Parity (PPP). According to this principle, the purchasing power of different currencies should tend to be the same. Right from its formulation, this principle was supposed to hold in the medium- and long-term. In fact, short-term violations of the PPP have been widely documented from the very early tests on, but recent studies present evidence supporting the PPP at longer time horizons. ${ }^{8}$ This implies that the real exchange rate between two currencies - which is related to the nominal exchange rate net of the difference between the price levels in the two corresponding countries - should be mean-reverting. In other words, the nominal exchange rate should offset the difference in the level of inflation between the two countries in order to bring the real exchange rate back to its long-term

\footnotetext{
7 Empirical evidence of positive autocorrelation for bond returns has been reported in several studies. For example, Siegel (2002) considers this phenomenon one of the main reasons why bonds are significantly less attractive than stocks in the long run. He provides some long-term statistics and further references on this subject.

8 See Campbell et al. (2003) for a survey of these studies.
} 


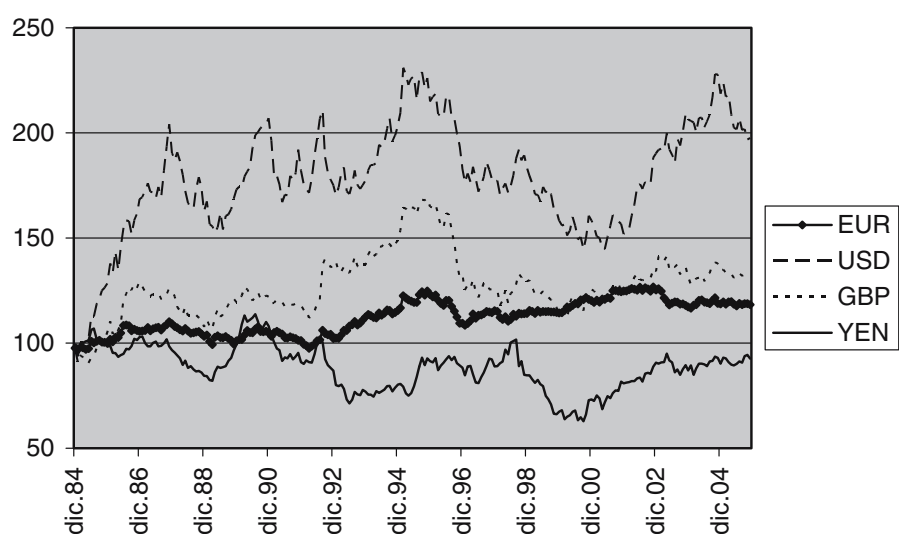

Fig. 2 Cumulative foreign exchange returns of the Swiss Franc (December $1984=100$ )

mean. Now, as already reported by Adler and Dumas (1983), “...price levels fluctuate little in comparison to exchange rates", so that the dynamics of nominal and real exchange rates tend to be similar. Therefore, if real exchange rates are mean-reverting - as assumed, among others, by Campbell et al. (2003) nominal exchange rates might well exhibit a similar behavior.

As recently confirmed by Campbell et al. (2003), “...mean-reversion in the real exchange rate is notoriously slow and hard to estimate over short sample periods..." and it is beyond the scope of this paper to provide a formal test of this hypothesis. Here, it suffices to say that the evidence reported in Fig. 1 is consistent with it. As an additional support for this hypothesis, we report in Fig. 2 the cumulative returns of the Swiss Franc against the four considered currencies. Cyclical patterns and reversion to previous values dominate the dynamics reported in Fig. 2 with a few exceptions (mainly, the depreciation of the US dollar and the British Pound during 1985 and 1986 and the depreciation of the German Mark during 1993).

The combined effect of these two observations is that the sum of all autocovariance terms in (12) calculated for 6-year periods is largely positive for bonds denominated in Swiss Francs, largely negative for the unhedged indices, and somewhere in between (therefore, not very sizeable) for the hedged indices. This, of course, has to lead to a drastic change in the level of volatility we obtained in Sect. 2.2 for the analysis of monthly excess returns, which did not consider the auto-covariance of these returns. The next section will provide clear evidence of this change.

\subsection{Historical results}

Our results for 1-year, 3-year, and 6-year periods are summarized in Table 5. None of these periods contain evidence of non-normality for the average monthly excess return. This is understandable since the average of even a relatively small sample tends to be normally distributed if the population is not 
Table 5 Results based on 1-year, 3-year, and 6-year periods (Period: 12/1984 - 12/2005)

\begin{tabular}{|c|c|c|c|c|c|c|c|c|}
\hline & $\begin{array}{l}\text { CHF } \\
\text { Bonds }\end{array}$ & $\begin{array}{l}\text { JPM } \\
\text { GA }\end{array}$ & $\begin{array}{l}\text { JPM GA } \\
\text { Hedged }\end{array}$ & $\begin{array}{l}\text { JPM } \\
\text { GT }\end{array}$ & $\begin{array}{l}\text { JPM GT } \\
\text { Hedged }\end{array}$ & $\begin{array}{l}\text { Balanced } \\
\text { Portfolio }\end{array}$ & $\begin{array}{l}\text { Balanced } \\
\text { Portfolio } \\
\text { Hedged }\end{array}$ & $\begin{array}{l}\text { Balanced } \\
\text { Portfolio } \\
\text { with Swiss } \\
\text { Bonds only }\end{array}$ \\
\hline $\begin{array}{l}\text { Average Monthly } \\
\text { Excess Return } \\
\text { Std. Deviation Ave }\end{array}$ & $\begin{array}{r}0.12 \% \\
\text { rage } \mathrm{Mo}\end{array}$ & $\begin{array}{r}0.20 \% \\
\text { nthly Ex }\end{array}$ & $\begin{array}{l}0.15 \% \\
\text { ess Return }\end{array}$ & $0.18 \%$ & $0.16 \%$ & $0.26 \%$ & $0.24 \%$ & $0.23 \%$ \\
\hline Over 1-year periods & $0.43 \%$ & $0.59 \%$ & $0.33 \%$ & $0.66 \%$ & $0.32 \%$ & $0.53 \%$ & $0.46 \%$ & $0.49 \%$ \\
\hline Over 3-year periods & $0.28 \%$ & $0.27 \%$ & $0.20 \%$ & $0.31 \%$ & $0.18 \%$ & $0.32 \%$ & $0.30 \%$ & $0.32 \%$ \\
\hline $\begin{array}{l}\text { Over 6-year periods } \\
\text { Sharpe Ratio Aver }\end{array}$ & $\begin{array}{l}0.20 \% \\
\text { age Mon }\end{array}$ & $\begin{array}{r}0.15 \% \\
\text { thly Ret }\end{array}$ & $\begin{array}{l}0.12 \% \\
\mathrm{rn}\end{array}$ & $0.19 \%$ & $0.10 \%$ & $0.20 \%$ & $0.19 \%$ & $0.21 \%$ \\
\hline $\begin{array}{l}\text { Over 1-year periods } \\
\text { (higher cost) }\end{array}$ & 0.28 & 0.34 & $0.45(0.42)$ & 0.27 & $0.49(0.46)$ & 0.48 & $0.53(0.52)$ & 0.48 \\
\hline$P$-value vs. hedged & & $27 \%$ & & $16 \%$ & & $21 \%$ & & $7 \%$ \\
\hline $\begin{array}{l}\text { Over 3-year periods } \\
\text { (higher cost) }\end{array}$ & 0.43 & 0.73 & $0.76(0.70)$ & 0.59 & $0.90(0.84)$ & 0.80 & $0.81(0.80)$ & 0.74 \\
\hline$P$-value vs. hedged & & $47 \%$ & & $23 \%$ & & $45 \%$ & & $5 \%$ \\
\hline $\begin{array}{l}\text { Over 6-year periods } \\
\text { (higher cost) }\end{array}$ & 0.60 & 1.35 & $1.25(1.16)$ & 0.96 & $1.67(1.56)$ & 1.33 & $1.29(1.27)$ & 1.13 \\
\hline$P$-value vs. hedged & & $55 \%$ & & $20 \%$ & & $57 \%$ & & $5 \%$ \\
\hline
\end{tabular}

Sample sizes are identical to those reported for Table 3. Average Excess Return, Standard Deviation of Average Excess Return and Sharpe Ratio are calculated on continuously compounded returns in accordance with Eqs. (11), (12), and (10), respectively. JPM GA and JPM GT indicate respectively global bond portfolios based on the regional weights of the JPM Global Active and the JPM Global Traded indices as of December 2005. The compositions of the balanced portfolios are identical to those reported for Table 4. Sharpe Ratios in parentheses assume hedging costs are higher by $0.125 \%$ p.a. The reported $P$-values refer to tests of the null hypothesis that the Sharpe Ratios of the tested portfolio and of the corresponding hedged portfolio are equal against the alternative hypothesis that the Sharpe Ratio of the hedged portfolio is higher

too far away from a normal distribution. The reported evidence of non-normality for monthly returns was significant but not overwhelming.

According to the results presented in Table 5, investing only in bonds denominated in Swiss Francs was clearly the least efficient strategy in terms of Sharpe Ratios. Like in our monthly analysis, the difference between the Sharpe Ratios of the balanced portfolio investing only in domestic bonds and of the hedged balanced portfolio is statistically significant at a $7 \%$ level for all considered time horizons. For time horizons of 1 year or longer, however, also unhedged investments in foreign currency bonds were generally more efficient than investments in domestic bonds. This remarkable difference compared with our monthly analysis is explained by the phenomena described in Sect. 3.2.: for monthly horizons, the unhedged JPM Global Active index displays a much higher standard deviation of monthly returns than bonds denominated in Swiss Francs (+79\%). For average returns over 6-year periods, the same index displays a visibly lower standard deviation of monthly returns than bonds denominated in Swiss Francs $(-25 \%)$.

The evidence reported in Table 5 is less clear-cut when we wish to compare hedged and unhedged investments in foreign currency bonds. Generally, we can say that-based on the $P$-values - the presumed superiority of hedged investments, which was not statistically significant over monthly periods, is even 
less significant over longer time periods. However, the two indices we analyzed provide us with opposite evidence. Over 6-year periods, the unhedged JPM Global Active index displays a higher Sharpe Ratio than the corresponding hedged index. Again, this difference compared with shorter time horizons is explained by the phenomena described in Sect. 3.2. However, the unhedged JPM Global Traded index clearly displays a lower Sharpe Ratio than the corresponding hedged index for all considered time horizons. These rankings remain unchanged when one considers the balanced portfolios.

The results presented in Table 5 are based on monthly returns defined as in (5). This formula assumes constant weights, which corresponds to a monthly rebalancing of the portfolios. However, corresponding results for buy-and-hold investors would look almost identical. ${ }^{9}$ Strong similarity of results between buyand-hold portfolios and portfolios rebalanced at constant weights has already been reported by Barberis (2000). Also, for the sake of brevity, we have not reported results of hedged portfolios with a hedge ratio lower than 1 (a hedge ratio that we assumed constant across all currencies). These results show that - for global bond portfolios - hedge ratios lower than 1 can lead to Sharpe Ratios higher than both unhedged and fully hedged portfolios, especially over 3 -year periods. However, this does not apply to balanced portfolios and applies only to a very small extent to 6-year periods.

The reason for the reported inconsistency between the results provided by the two analyzed indices will be explained in Sect. 3.4. Here, it suffices to remind that the main difference between the two indices consists of the amount of investments in bonds denominated in US dollars. Also, the US dollar was by far the most important reference currency for the global financial and trading flows in the period we analyzed. This unique role of the US dollar could have led this currency to display a peculiar behavior relatively to all other currencies. On this basis, it appears plausible to test bond portfolios that include systematic hedging of foreign currency risk only on the US dollar. The results of these tests are reported in Table 6 . In this case, the differences between the two hedging cost scenarios are negligible, so that we decided to report only the values for the basis scenario.

Table 6 confirms that the US dollar was indeed the main reason for the reported inconsistency between the results provided by the two analyzed indices. The strategy of hedging only the exposure to the US dollar would have provided our investor with a less (more) efficient portfolio than a full hedging strategy over 1-year (6-year) periods. This ranking inversion on longer time horizons is now consistent for both indices and for the balanced portfolios. We have, however, to ask ourselves how much this conclusion is due to specific

9 We estimated the standard deviation of average excess returns for buy-and-hold portfolios as $\hat{\sigma}_{r, A}^{(k)}=\sqrt{E\left[\sum_{i=1}^{N} w_{i, A}\left(r_{i}-r_{f}-\hat{\mu}_{r, i}\right)\right]^{2}}$.

The variance and covariance terms implicit in the last expression have been adjusted for serial correlation by using the $N$-dimensional version of formulas (12) and (13) applied to the vector process of the returns of the $N$ indices in which portfolio $A$ invests. 
Table 6 Bond portfolios hedging only the exposure to the US \$ (Period: 12/1984 - 12/2005)

\begin{tabular}{llll}
\hline & $\begin{array}{l}\text { JPM GA with } \\
\text { Hedged US\$ }\end{array}$ & $\begin{array}{l}\text { JPM GT with } \\
\text { Hedged US\$ }\end{array}$ & $\begin{array}{l}\text { Balanced Portfolio } \\
\text { with Hedged US\$ }\end{array}$ \\
\hline Average Monthly Excess Return & $\begin{array}{l}0.20 \% \\
\text { Std. Deviation Average Monthly Excess Return } \\
0.55 \%\end{array}$ & $0.20 \%$ & $0.26 \%$ \\
Over 1-year periods & $0.25 \%$ & $0.49 \%$ & $0.52 \%$ \\
Over 3-year periods & $0.13 \%$ & $0.22 \%$ & $0.32 \%$ \\
Over 6-year periods & 0.37 & $0.10 \%$ & $0.19 \%$ \\
Sharpe Ratio Average Monthly Return & & \\
Over 1-year periods & $32 \%$ & 0.41 & 0.50 \\
$P$-value vs. hedged & 0.80 & $31 \%$ & $28 \%$ \\
Over 3-year periods & $55 \%$ & 0.91 & 0.82 \\
$P$-value vs. hedged & 1.63 & $51 \%$ & $53 \%$ \\
Over 6-year periods & $63 \%$ & 2.09 & $66 \%$ \\
$P$-value vs. hedged & $59 \%$ &
\end{tabular}

Sample sizes are identical to those reported for Table 3. Average Excess Return, Standard Deviation of Average Excess Return and Sharpe Ratio are calculated using continuously compounded returns in accordance with (11), (12), and (10), respectively. JPM GA and JPM GT indicate respectively global bond portfolios based on the regional weights of the JPM Global Active and the JPM Global Traded indices as of December 2005. The Balanced Portfolio includes 10\% investment in Swiss equities and $10 \%$ unhedged investment in foreign equities. The remaining $80 \%$ of the portfolio is invested in bonds denominated in Swiss Francs (50\%) and in the JPM GA (30\%), hedging only the exposure to the US dollar. The reported $P$-values refer to tests of the null hypothesis that the Sharpe Ratios of the tested portfolio and of the corresponding fully hedged portfolio are equal against the alternative hypothesis that the Sharpe Ratio of the fully hedged portfolio is higher

characteristics of our data set, which are unlikely to be observed again in the future. This question is particularly justified since most of our results are not statistically significant. Section 3.4 of this paper focuses on this question.

\subsection{Results based on the Uncovered Interest Rate Parity}

A first criticism that could be made to the results presented in Sect. 3.3 for the JPM Global Active index is that they are heavily influenced by a violation of the principle of Uncovered Interest Rate Parity. This principle has been found to hold in the long term. Even studies that reported the plausible existence of a risk premium (Hansen and Hodrick (1980)) indicated that the average longterm value of this premium was close to zero. As a consequence, the return obtained from hedged investments (gross of hedging costs) should equal in the long-term the return obtained from unhedged investments.

On this basis, we decided to assess how much the results presented in Sect. 3.3 would change under the hypothesis that the Uncovered Interest Rate Parity had held in the past. We performed this assessment by imposing an average return for hedged bond positions equal to the average return provided by unhedged bond positions, less the costs of hedging assumed in Sect. 1.5. For the standard deviation, we continued to use the historical estimates presented in Sect. 3.3.

The results obtained for the hedged portfolios under the principle of Uncovered Interest Rate Parity are reported in Table 7. This evidence is now consistent for both indices: hedged portfolios were more efficient than unhedged 
Table 7 Hedged bond portfolios under the principle of Uncovered Interest Rate Parity (period: 12/1984 - 12/2005)

\begin{tabular}{lllllll}
\hline & JPM & JPM GA \\
GA & Hedged & $\begin{array}{l}\text { JPM } \\
\text { Hedged } \\
\text { US\$ }\end{array}$ & $\begin{array}{l}\text { GT } \\
\text { Hedged }\end{array}$ & $\begin{array}{l}\text { JPM } \\
\text { GT with } \\
\text { Hedged } \\
\text { US\$ } \$\end{array}$ & $\begin{array}{l}\text { Balanced } \\
\text { Portfolio } \\
\text { Hedged }\end{array}$ & $\begin{array}{l}\text { Balanced } \\
\text { Portfolio } \\
\text { with Hedged } \\
\text { US\$ }\end{array}$ \\
\hline $\begin{array}{l}\text { Average Monthly Excess Return } \\
\text { Sharpe Ratio Average Monthly Return }\end{array}$ & $0.17 \%$ & $0.20 \%$ & $0.16 \%$ & $0.18 \%$ & $0.25 \%$ & $0.26 \%$ \\
$\begin{array}{l}\text { Over 1-year periods (higher cost) } \\
\text { Over 3-year periods (higher cost) }\end{array}$ & $\begin{array}{l}0.53(0.50) \\
\text { Over 6-year periods (higher cost) }\end{array}$ & $0.36(0.36)$ & $0.48(0.45)$ & $0.36(0.35)$ & $0.54(0.54)$ & $0.49(0.49)$ \\
\hline
\end{tabular}

Average Excess Return for hedged bond positions was calculated as the average excess return provided by unhedged bond positions (as in Table 5) less the costs of hedging assumed in Sect. 1.5. The Standard Deviation of Average Excess Return is the same as in Tables 5 and 6. Sharpe Ratios in parentheses assume hedging costs are higher by $0.125 \%$ p.a

portfolios. The most efficient strategy for long-term investors was, however, still the one of hedging only the exposure to the US dollar. On the basis of Tables 6 and 7 , we can conclude that one main reason for the inconsistency of the results observed on the two indices was the violation of the Uncovered Interest Rate Parity, particularly for the US dollar.

A second criticism to our analysis could be based on the fact that the 21-year period we analyzed is a relatively short period characterized by very special events, such as the convergence to the Euro or the equity markets bubble. We should, therefore, question whether the estimates of risk we based on this period are valid representations of what we expect for the future.

This criticism is justified. A partial answer to it is to perform a sub-sample analysis. The results of this analysis are reported in Table 8 . These results highlight some clear differences between the two sub-samples. As already shown in Sect. 2.2, bonds denominated in Swiss Francs performed extremely poorly in the first sub-sample and extremely well in the second sub-sample. This result is amplified over longer time horizons, since the positive auto-covariance of excess returns for these bonds is very low in the second sub-sample. As a result, the balanced portfolio investing only in bonds denominated in Swiss Francs appears to be the best balanced portfolio for long-term investors in the second sub-sample.

Another striking result displayed by this sub-sample analysis is the relatively poor performance of the unhedged portfolios in the second sub-sample. This is mainly due to the fact that the auto-covariance of excess returns for unhedged bonds is, for most currencies, significantly higher in the second sub-sample.

The two sub-samples, however, provide consistent results on two important tests for long-term investors. Hedging only bonds denominated in US dollars would have led in both sub-periods to equal or better risk-adjusted results than unhedged bonds. Also, balanced portfolios with hedging limited to bonds denominated in US dollars would have led in both sub-periods to equal or better long-term risk-adjusted results than other portfolios containing foreign currency bonds. It is interesting to note that this is also true in the second sub-sample in which full hedging would have provided the best result on the JPM GA index taken on its own. 
Table 8 Hedged bond portfolios under the principle of Uncovered Interest Rate Parity Sub-sample analysis (first sub-sample: 12/1984 - 05/1993 and Second sub-sample: 06/1993 - 12/2005)

\begin{tabular}{|c|c|c|c|c|c|c|}
\hline & \multicolumn{3}{|c|}{ First sub-sample } & \multicolumn{3}{|c|}{ Second sub-sample } \\
\hline & $\begin{array}{l}\text { Over 1-year } \\
\text { periods }\end{array}$ & $\begin{array}{l}\text { Over 3-year } \\
\text { periods }\end{array}$ & $\begin{array}{l}\text { Over 6-year } \\
\text { periods }\end{array}$ & $\begin{array}{l}\text { Over 1-year } \\
\text { periods }\end{array}$ & $\begin{array}{l}\text { Over 3-year } \\
\text { periods }\end{array}$ & $\begin{array}{l}\text { Over 6-year } \\
\text { periods }\end{array}$ \\
\hline \multicolumn{7}{|c|}{ Sharpe Ratio Average Monthly Return } \\
\hline CHF Bonds & $\mathrm{NM}$ & NM & NM & 0.70 & 1.51 & 6.70 \\
\hline JPM GA & 0.17 & 0.44 & 0.75 & 0.52 & 0.97 & 3.09 \\
\hline $\begin{array}{l}\text { JPM GA Hedged } \\
\text { (higher cost) }\end{array}$ & $0.26(0.23)$ & $0.39(0.35)$ & $0.72(0.64)$ & $0.81(0.77)$ & $2.02(1.93)$ & $4.77(4.55)$ \\
\hline $\begin{array}{l}\text { JPM GA with } \\
\text { Hedged US\$ }\end{array}$ & 0.18 & 0.42 & 0.77 & 0.57 & 1.08 & 4.18 \\
\hline JPM GT & 0.09 & 0.27 & 0.42 & 0.46 & 0.81 & 1.89 \\
\hline JPM GT Hedged (higher cost) & $0.14(0.11)$ & $0.22(0.17)$ & $0.40(0.32)$ & $0.80(0.76)$ & $2.20(2.10)$ & $6.27(5.98)$ \\
\hline JPM GT with & $0.11(0.11)$ & $0.25(0.24)$ & $0.51(0.49)$ & $0.66(0.65)$ & $1.33(1.32)$ & $4.58(4.53)$ \\
\hline \multicolumn{7}{|l|}{ Hedged US\$ (higher cost) } \\
\hline $\begin{array}{l}\text { Balanced Portfolio } \\
\text { with Swiss Bonds only }\end{array}$ & 0.11 & 0.19 & 0.28 & 0.84 & 1.30 & 3.42 \\
\hline Balanced Portfolio & 0.20 & 0.41 & 0.60 & 0.74 & 1.14 & 3.02 \\
\hline Balanced Portfolio & $0.22(0.21)$ & $0.38(0.37)$ & $0.58(0.57)$ & $0.84(0.84)$ & $1.30(1.29)$ & $3.02(2.99)$ \\
\hline Hedged (higher cost) & & & & & & \\
\hline $\begin{array}{l}\text { Balanced Portfolio } \\
\text { with Hedged US\$ }\end{array}$ & 0.20 & 0.40 & 0.60 & 0.76 & 1.16 & 3.14 \\
\hline
\end{tabular}

Average Excess Return for hedged bond positions has been calculated as the average excess return provided by unhedged bond positions less the costs of hedging assumed in 1.5. Not meaningful (NM) is reported in the case of negative Sharpe Ratio. Ratios in parentheses assume hedging costs are higher by $0.125 \%$ p.a. They have been reported only when the difference from the ratios in the basis scenario was relevant

The reason for the latter observation is that unhedged foreign currency bonds display a far lower covariance with bonds denominated in Swiss Francs than hedged foreign currency bonds. This is true not only for contemporaneous observations but also for lagged observations, so that this effect is amplified when we focus on longer time horizons. It is true that unhedged foreign currency bonds display a far higher covariance with foreign stocks than hedged foreign currency bonds. For the balanced portfolio we tested, however, this plays a smaller role than the covariance with bonds denominated in Swiss Francs. Our robustness tests (not reported for the sake of brevity) show that -if bonds denominated in Swiss Francs represent at least $50 \%$ of the portfolio-the effect of the covariance with these bonds will tend to overwhelm the effect of the covariance with foreign equities. This favors unhedged foreign currency bonds over hedged foreign currency bonds for longer time horizons.

\section{Conclusions}

\subsection{The case for foreign currency bonds}

The results reported in this paper provide evidence in favor of hedged foreign currency bonds against the alternative hypothesis of investing only in bonds denominated in Swiss Francs. If we consider the last 21 years as a whole, 
investing in bonds denominated in Swiss Francs has been clearly less efficient in terms of risk-adjusted returns than investing in a hedged global bond portfolio. This conclusion holds independent of the time horizon of the investment. This should not be surprising considering that global bond portfolios display a much higher level of diversification than a portfolio investing only in bonds denominated in Swiss Francs.

As usual for this type of empirical analysis, sub-samples display very different results. However, the superiority of global bond portfolios across the whole data set is supported by high levels of statistical significance. If we add to these quantitative considerations the fact that the Swiss Franc bond market is significantly less liquid than the other major bond markets, especially in the corporate bond sector, and that it offers far less diversification opportunities among bond issuers, we claim that it is difficult to find strong arguments against a global diversification of bond investments for a Swiss investor without significant predicting ability. This conclusion is consistent with Haefliger et al. (2002) as well as with Zucchinetti et al. (1995).

\subsection{The case for unhedged foreign currency bonds}

The empirical evidence we collected is far less clear-cut as for the opportunity of hedging investments in foreign currency bonds. Partially, this is due to the fact that tests on the significance of the difference between Sharpe Ratios of the type we used have a relatively low power on a data sample with the size of ours. ${ }^{10}$ This leads even sizeable differences not to be highly statistically significant. Nevertheless, we believe that some of our results can provide investors, who are forced to take decisions on this crucial matter, with quite a robust guidance.

For short-term investors, our analysis provides robust evidence against the hypothesis of investing in unhedged foreign currency bonds. The additional volatility caused by changing foreign exchange rates is clearly not sufficiently compensated for this type of investor. This is true for all indices and portfolios we considered, for all time horizons up to one year, and for both sub-samples we analyzed. Additionally, this conclusion is true for both historical returns and returns of hedged foreign currency bonds based on the Uncovered Interest Rate Parity, and it is robust to reasonable increases in hedging costs.

The picture changes dramatically, however, when we consider an investment horizon of 6 years and the normal case of balanced portfolios including also

\footnotetext{
10 High standard errors for Sharpe Ratios including the autocovariance terms have also been highlighted by Lo (2002), who recommends including these terms only in presence of very significant autocorrelation. As we show in this paper, these terms have an important and consistent effect on the Sharpe Ratios we estimated. Accordingly, they should always be included for analyses like the ones we perform here. The drastic reduction of long-term volatility and the size of the autocovariance also for quite high values of $j$ (highlighted by Fig. 1) lead long-term Sharpe Ratios for unhedged foreign currency bonds to display particularly high standard errors.
} 
equities and domestic bonds. In this case, the optimal strategy for the period we analyzed would have been to hedge only the exposure to the US dollar. Again, this result is true for both indices and for both sub-samples we analyzed and holds under both historical returns and returns based on the Uncovered Interest Rate Parity as well as under different assumptions for hedging costs.

We find our evidence that long-term investors should not hedge foreign currency risk - with the exception of the US dollar-nicely consistent with two well-known economic principles which have been found to hold in the longterm. The Uncovered Interest Rate Parity implies that the gross return obtained from hedged investments should equal the return obtained from unhedged investments. Therefore, the return obtained from hedged investments net of hedging costs should be lower. The Purchasing Power Parity implies that the real exchange rate between two currencies should be mean-reverting, thus leading to a drastic reduction of long-term volatility for unhedged foreign currency bonds. Moreover, when we hedge foreign currency bonds within a portfolio including domestic bonds, this tends to drastically increase the covariance between the two asset classes, thus reducing the efficiency of the portfolio.

However, if all these economic factors do really play an important role in the long-term, why does this not apply to the US dollar as well? We see two possible explanations. Firstly, the US dollar was by far the most important reference currency for the global financial and trading flows in the period we analyzed. It is well-known that this allowed the US to manage their twin deficits in a way that was substantially different from any other country, thus leading their currency to display a very peculiar behavior. Secondly, the size of our data set did not allow us to test time horizons longer than 6 years. It may well be that-over longer time horizons - the above-mentioned economic factors make even the hedging of the US dollar no longer an optimal choice.

Acknowledgements The paper was substantially improved thanks to the contribution of two anonymous referees. The author alone is responsible for all the weaknesses the paper may still present.

\section{Appendix}

If we insert our definition (9) of continuously compounded monthly rates of return into (8), we obtain:

$$
\begin{aligned}
\left(1+R_{t, A}^{(k)}\right)^{k} & =\mathrm{e}^{r_{t, A}} \mathrm{e}^{r_{t-1, A}} \mathrm{e}^{r_{t-2, A}} \mathrm{e}^{r_{t-3, A}} \mathrm{e}^{r_{t-4, A}} \cdots \mathrm{e}^{r_{t-k+1, A}} \quad \text { and } \\
k \ln \left(1+R_{t, A}^{(k)}\right) & =\sum_{i=1}^{k} r_{t-i+1, A}
\end{aligned}
$$


Since the absolute value of monthly compounded average monthly returns provided over more than 12 months by portfolios composed exclusively or mainly of bonds hardly exceeds $1.7 \%$, we can apply Taylor approximation, obtaining the following result:

$$
R_{t, A}^{(k)} \approx \frac{1}{k} \sum_{i=1}^{k} r_{t-i+1, A}
$$

If we now introduce the following definition of the monthly compounded average monthly return provided by the risk-free investment on a time horizon of $k$ months ending at month $t$ :

$$
\left(1+R_{t, f}^{(k)}\right)^{k}=\mathrm{e}^{r_{t, f}} \mathrm{e}^{r_{t-1, f}} \mathrm{e}^{r_{t-2, f}} \mathrm{e}^{r_{t-3, f}} \mathrm{e}^{r_{t-4, f}} \cdots \mathrm{e}^{r_{t-k+1, f}}
$$

and we apply Taylor approximation as above, we obtain the following formulation of the monthly compounded average monthly excess return:

$$
R_{t, A}^{(k)}-R_{t, f}^{(k)} \approx \frac{1}{k} \sum_{i=1}^{k}\left(r_{t-i+1, A}-r_{t-i+1, f}\right)
$$

In order to estimate the efficiency of a specific portfolio, we estimate the average and the standard deviation of the previous expression. For the average, we obtain from (18):

$$
\mu_{R, A}^{(k)} \equiv E\left[R_{t, A}^{(k)}-R_{t, f}^{(k)}\right] \approx E\left[\frac{1}{k} \sum_{i=1}^{k}\left(r_{t-i+1, A}-r_{t-i+1, f}\right)\right] \equiv \mu_{r, A}^{(k)}
$$

and the value of the latter expression is estimated as described in (11). If we apply equations (18) and (19) to the definition of the standard deviation, we obtain

$$
\begin{aligned}
\sigma_{R, A}^{(k)} & \equiv \sqrt{E\left[R_{t, A}^{(k)}-R_{t, f}^{(k)}-\mu_{R, A}^{(k)}\right]^{2}} \approx \sqrt{E\left[\frac{1}{k} \sum_{i=1}^{k}\left(r_{t-i+1, A}-r_{t-i+1, f}\right)-\mu_{r, A}\right]^{2}} \\
& \equiv \sigma_{r, A}^{(k)}
\end{aligned}
$$


If we consider the auto-covariance of excess returns, we have

$$
\begin{aligned}
& E\left[\frac{1}{k} \sum_{i=1}^{k}\left(r_{t-i+1, A}-r_{t-i+1, f}\right)-\mu_{r, A}\right]^{2} \\
& \quad=\frac{1}{k}\left[\gamma_{0, A}+2 \frac{k-1}{k} \gamma_{1, A}+2 \frac{k-2}{k} \gamma_{2, A}+\cdots+2 \frac{1}{k} \gamma_{k-1, A}\right]
\end{aligned}
$$

with

$$
\gamma_{j, A} \equiv E\left[\left(r_{t, A}-r_{t, f}-\mu_{r, A}\right)\left(r_{t-j, A}-r_{t-j, f}-\mu_{r, A}\right)\right]
$$

The last two equations are estimated as described in (12) and (13).

\section{References}

Adler, M., Dumas B.: International portfolio choice and corporate finance: a synthesis. J. Finance 38, 925-984 (1983)

Barberis, N.C.: Investing for the long run when returns are predictable. J. Finance 55, 225-264 (2000)

Black, F.: Universal hedging: optimising currency risk and reward in international equity portfolios. Finan. Analysts J. July-August (1989)

Campbell, J.Y., Lo, A.W., MacKinlay, A.C.: The Econometrics of Financial Markets. Princeton University Press, Princeton (1997)

Campbell, J.Y., Viceira, L.M., White, J.S.: Foreign currency for long-term investors. Econ. J. 113 (March), C1-C25 (2003)

Froot, K.: Currency hedging over long horizons: National Bureau of Economic Research Working Paper No. 4355, Cambridge, MA (1993)

Gastineau, G.: The currency hedging decision: a search for synthesis in asset allocation. Finan. Analysts J. 51 (May-June), 8-17 (1995)

Greshin, A.M., Hadzima, M.D.: International bond investing and portfolio management. In: Fabozzi, F.J. (ed.) The Handbook of Fixed Income Securities, 3rd edn. pp. 1086-1122. Business One Irwin, New York, NY (1991)

Haefliger, T., Wälchli, U., wydler, D.: Hedging currency risk: does it have to be so complicated? SSRN Working Paper No. 363080 (2002)

Hansen, L.P., Hodrick, R.J.: Forward rates as optimal predictors of future spot rates. J. Polit. Econ. (October), 829-853 (1980)

Lo, A.W.: The statistics of sharpe ratios. Financ. Analysts J. (July/August), 36-52 (2002)

Markowitz, H.: Portfolio selection. J. Finance 7, 77-91 (1952)

Perold, A., Schulman, E.: The free lunch in currency hedging: implications for investment policy and performance standards. Finan. Analysts J. (May-June), 45-50 (1988)

Rosenberg, M.R.: International fixed income investing: theory and practice. In: Fabozzi, F.J. (ed.) The Handbook of Fixed Income Securities, 3rd edn., pp. 1123-1154. Business One Irwin, New York, NY (1991)

Sharpe, W.: Portfolio Theory and Capital Markets. McGraw-Hill, New York, NY (1970)

Siegel, J.J.: Stocks for the Long Run. McGraw-Hill, New York, NY (2002)

Zucchinetti, S., Solnik, B., Odier, P.: Global optimization for Swiss pension funds. Finan. Markets Portfo. Manage. 9, 210-231 (1995) 


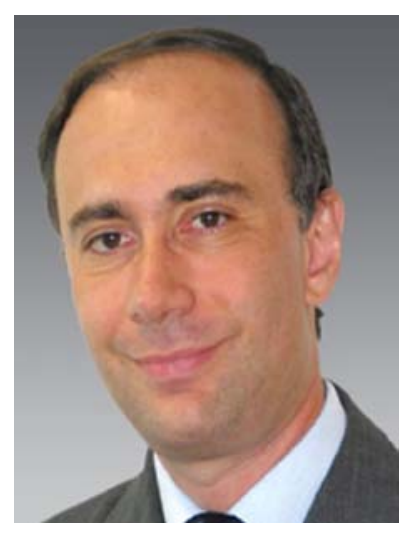

Nicola Carcano teaches Structured Products at the Università della Svizzera Italiana, Lugano. He holds a degree in Economics from LUISS University, Rome, a MBA degree from New York University, and a Ph.D. in Financial Markets Theory from University of St. Gallen (HSG). He started his professional career in 1987 with Andersen Consulting (today Accenture) as a consultant to Swiss banks and other financial service companies. Between 1994 and 1999, he led the Quantitative Finance Team of the Investment Banking Department of UBS in Zurich. Between 1999 and 2006, he was responsible for Institutional Asset Management at BSI in Lugano. Since 2006, he is Head of Mercer Investment Consulting in Italy. 